\title{
Population Genetic Structure of Qol-Resistant Pestalotiopsis longiseta Isolates Causing Tea Gray Blight
}

Kengo Yamada, NARO Institute of Vegetable and Tea Science, National Agriculture and Food Research Organization (NARO), Shimada, Shizuoka 428-8501, Japan; Ryoichi Sonoda, National Institute for Agro-Environmental Sciences, Tsukuba, Ibaraki 305-8604, Japan; and Koichi Ishikawa, NARO Institute of Vegetable and Tea Science, National Agriculture and Food Research Organization (NARO), Shimada, Shizuoka 428-8501, Japan

\begin{abstract}
Yamada, K., Sonoda, R., and Ishikawa, K. 2016. Population genetic structure of QoI-resistant Pestalotiopsis longiseta isolates causing tea gray blight. Plant Dis. 100:1686-1691.

Resistance to the quinone outside inhibitor (QoI) fungicides in the tea gray blight-causing fungus Pestalotiopsis longiseta is a serious problem in Japanese tea cultivation. We conducted a population genetic analysis of QoI-resistant $P$. longiseta isolates on the Makinohara Plateau, Shizuoka Prefecture, Japan's largest tea-growing area, to elucidate the disease's epidemiology and the spread of QoI resistance. Inter simple sequence repeat (ISSR) analysis of 1,083 isolates from 395 fields collected from 2009 to 2012 detected 42 ISSR types, designated as PL01 to PL42. A total of 18 , seven, and 38 ISSR types were detected in highly resistant, moderately resistant, and sensitive isolates, respectively. No distinct phylogenetic

relationship corresponding to QoI sensitivity or sampling location was observed. No annual changes in the population genetic structure of highly resistant isolates were observed during the study period. A different ISSR type was predominant among QoI-resistant isolates in each region. Analysis of molecular variance revealed significant genetic differentiation in populations of highly resistant isolates among regions $\left(F_{C T}=0.213\right)$ and farmers $\left(F_{C T}=0.071\right)$. Consequently, we speculate that QoI-resistant $P$. longiseta strains occurred in a number of clonal lineages and spread by both natural and artificial transmission, such as rain splash and plucking machines, throughout each region on the Makinohara Plateau.
\end{abstract}

The anamorphic ascomycete Pestalotiopsis longiseta (Speg.) K. Dai \& Tak. Kobay. causes gray blight, which is one of the most important diseases of tea [Camellia sinensis (L.) O. Kuntze] in Japan (Ezuka and Ando 1994; Hamaya and Horikawa 1982). Gray blight became a common serious disease in the 1970s with the spread of machine plucking and the Yabukita cultivar, which is susceptible to the disease (Hamaya and Horikawa 1982). At present, gray blight occurs in all major tea-growing areas throughout the country, typically after the second and third crop harvestings from June to August (Ezuka and Ando 1994). The pathogen infects tea through wounds on the leaves and stems; rough wounds on leaves caused by machine plucking are particularly susceptible to infection (Horikawa 1984). Typical symptoms of gray blight appear at wounds on leaves as large brown, circular or V-shaped necrotic lesions characterized by a concentric zonation (Hamaya and Horikawa 1982). Infection also occurs at naturally formed wounds on the basal part of young shoots. This type of infection inhibits water supply to the upper part of the plant and causes shoot blight symptoms (Ando et al. 1987). Gray blight causes defoliation and stem blight, resulting in a decline in tree vitality (Horikawa 1986a).

Control of gray blight relies on chemical fungicides, with spraying immediately after machine plucking being necessary for sufficient control (Horikawa 1982). Of the effective fungicides against gray blight, methyl benzimidazole carbamate (MBC) fungicides, such as thiophanate-methyl and benomyl, were the preferred chemicals because of their acute and curative effect (Horikawa 1982). However, they were eventually disabled with the development of MBCresistant strains in the 1980s (Horikawa 1986b; Oniki et al. 1986). Subsequently, azoxystrobin, a kind of strobilurin that belongs to a class of the quinone outside inhibitor (QoI) fungicides, was introduced

Corresponding author: K. Yamada, E-mail: kenyama@affrc.go.jp

Accepted for publication 23 March 2016

http://dx.doi.org/10.1094/PDIS-09-15-1114-RE

C 2016 The American Phytopathological Society to tea cultivation in 1998 and replaced MBC fungicides as a curative fungicide against gray blight (Togawa 2014; Tomihama et al. 2009).

QoI fungicides are the most important class of agricultural fungicides because of their high control efficacy against a broad range of plant-pathogenic fungi (Bartlett et al. 2002). They inhibit mitochondrial respiration by binding at the Qo site of cytochrome $b$, which is the part of the complex III located in the inner mitochondrial membrane (Bartlett et al. 2002). Because of their single-site mode of action, QoI fungicides are classified as high risk for the development of resistance in pathogens (Brent and Hollomon 2007). Field isolates of fungal plant pathogens resistant to QoI fungicides were first found in Blumeria graminis f. sp. tritici, which causes powdery mildew in wheat, in Germany in 1998 (Heaney et al. 2000). Since then, field resistance to QoI fungicides has been reported in over 40 species of fungal plant pathogens (Fungicide Resistance Action Committee 2013).

QoI resistance is generally caused by single amino acid substitutions in QoI-targeted cytochrome $b$ encoded by the mitochondrial $c y t b$ gene (Gisi et al. 2002). The substitution of glycine by alanine at amino acid position 143 (G143A) is the most common type of causal mutation for field resistance. Additionally, replacement of phenylalanine by leucine at position 129 (F129L) and glycine by arginine at position 137 (G137R) also cause QoI resistance. However, the latter two substitutions lead to lower QoI resistance than the G143A mutation and rarely result in a serious problem in the field (Fernández-Ortuño et al. 2010).

QoI resistance in $P$. longiseta was first found in Kagoshima Prefecture, Japan in 2008 (Tomihama et al. 2009). Subsequent investigations revealed that QoI-resistant strains were already widely distributed in Shizuoka Prefecture, the largest tea-growing prefecture in Japan (Sonoda and Yamada 2012; Togawa et al. 2010). Two types of QoI resistance resulting from the G143A and F129L mutations have been reported in P. longiseta (Tomihama et al. 2009; Yamada and Sonoda 2012). G143A mutants are highly resistant (HR) to QoI fungicides and widespread in Kagoshima and Shizuoka, whereas F129L mutants are moderately resistant (MR) and have only been detected in a small area of Shizuoka (Yamada and Sonoda 2012). Although QoI resistance has not been found in other prefectures, it will presumably occur anywhere QoI fungicides are used because 
of the high risk of resistance development (Brent and Hollomon 2007). Information on the QoI resistance route of spread is important to prevent the spread of QoI resistance in other regions and to understand the epidemiology of $P$. longiseta. In this study, we have attempted DNA fingerprinting of $P$. longiseta by inter simple sequence repeat (ISSR) analysis and population genetics analysis of QoIresistant isolates collected on the Makinohara Plateau, Shizuoka Prefecture, the largest tea-growing area in Japan, to elucidate the route of spread of QoI resistance of $P$. longiseta.

\section{Materials and Methods}

Fungal isolates. $P$. longiseta isolates collected through our previous studies (Sonoda and Yamada 2012; Yamada and Sonoda 2012) were used for current genetic testing. They were isolated from gray blight lesions on tea leaves collected from tea fields on the Makinohara Plateau, Shizuoka Prefecture, Japan from 2009 to 2012 (Fig. 1). The study fields were divided into four regional groups as follows: Shimada (the northern part), Yoshida (the eastern part), Makinohara (the middle to southeastern part), and Omaezaki (the southern part) (Fig. 1). These regional groups were set based on the relative positions of the fields and almost correspond to municipalities. Diseased tea leaves were randomly sampled from an entire field on one occasion. The samples were collected again the following year in the same 15 fields in Omaezaki and 12 fields in Shimada to analyze the annual changes in population genetic structure. QoI sensitivity was assayed by the agar plate dilution method according to a previous study (Yamada and Sonoda 2012). The isolates that grew to $>10 \mathrm{~mm}$ in diameter on potato dextrose agar (PDA) (Eiken Chemical, Tokyo) containing the QoI fungicide azoxystrobin $(100 \mathrm{mg} / \mathrm{liter})$ and $n$-propyl gallate $(2 \mathrm{mM})$ as an alternative oxidase inhibitor (Hollomon et al. 2005) after 4 days at $25^{\circ} \mathrm{C}$ were considered HR.
Isolates in which growth was completely inhibited after 7 days were considered sensitive (S). Isolates that exhibited intermediate growth were considered MR. Single spore isolates were obtained from the plates after the assays. For long-term preservation, conidia were swabbed with sterile filter paper and were maintained at $4^{\circ} \mathrm{C}$ or below with silica gels. Of the 1,082 isolates from 395 fields examined in this study, 623 isolates from 244 fields were HR, 64 isolates from 27 fields were MR, and the remaining 395 isolates from 319 fields were $\mathrm{S}$ to QoI fungicides. Both the sensitive and resistant isolates were examined in 171 of the 233 fields in which both were detected.

Genotyping of the cytb gene mutations was carried out on at least one isolate for every combination of QoI sensitivity, as assigned by the plate test described above, and ISSR type, by multiplex polymerase chain reaction (PCR) restriction fragment length polymorphism, as described previously (Yamada and Sonoda 2012). All of the HR and MR isolates tested were identified as either the G143A or F129 L mutant, respectively, and $\mathrm{S}$ isolates were the wild type.

DNA extraction and ISSR amplification. Fungal isolates were grown on a sterile cellophane film put on PDA at $25^{\circ} \mathrm{C}$ in the dark for 3 to 4 days. Mycelia were collected with a microspatula, were lyophilized, and were disrupted with a Mini-Beadbeater-8 (BioSpec Products, Bartlesville, OK) after lyophilization. DNA was extracted with an E.Z.N.A. fungal DNA mini kit (Omega Bio-Tek, Norcross, GA) according to the manufacturer's protocol. DNA concentrations were determined by ethidium bromide staining after electrophoresis. ISSR amplification was performed using three $5^{\prime}$-anchored ISSR primers, CGA [DHB(CGA) 5 , CCA [DD $\left.(\mathrm{CCA})_{5}\right]$, and GT [VHV $\left.(\mathrm{GT})_{5} \mathrm{G}\right]$ (Hantula et al. 1996). The PCR mixture contained $1 \times$ HotStarTaq plus master mix (Qiagen, Hilden, Germany), $1 \times$ CoralLoad Concentrate (Qiagen), $0.4 \mu \mathrm{M}$ of primer, and $5 \mathrm{ng}$ of template DNA
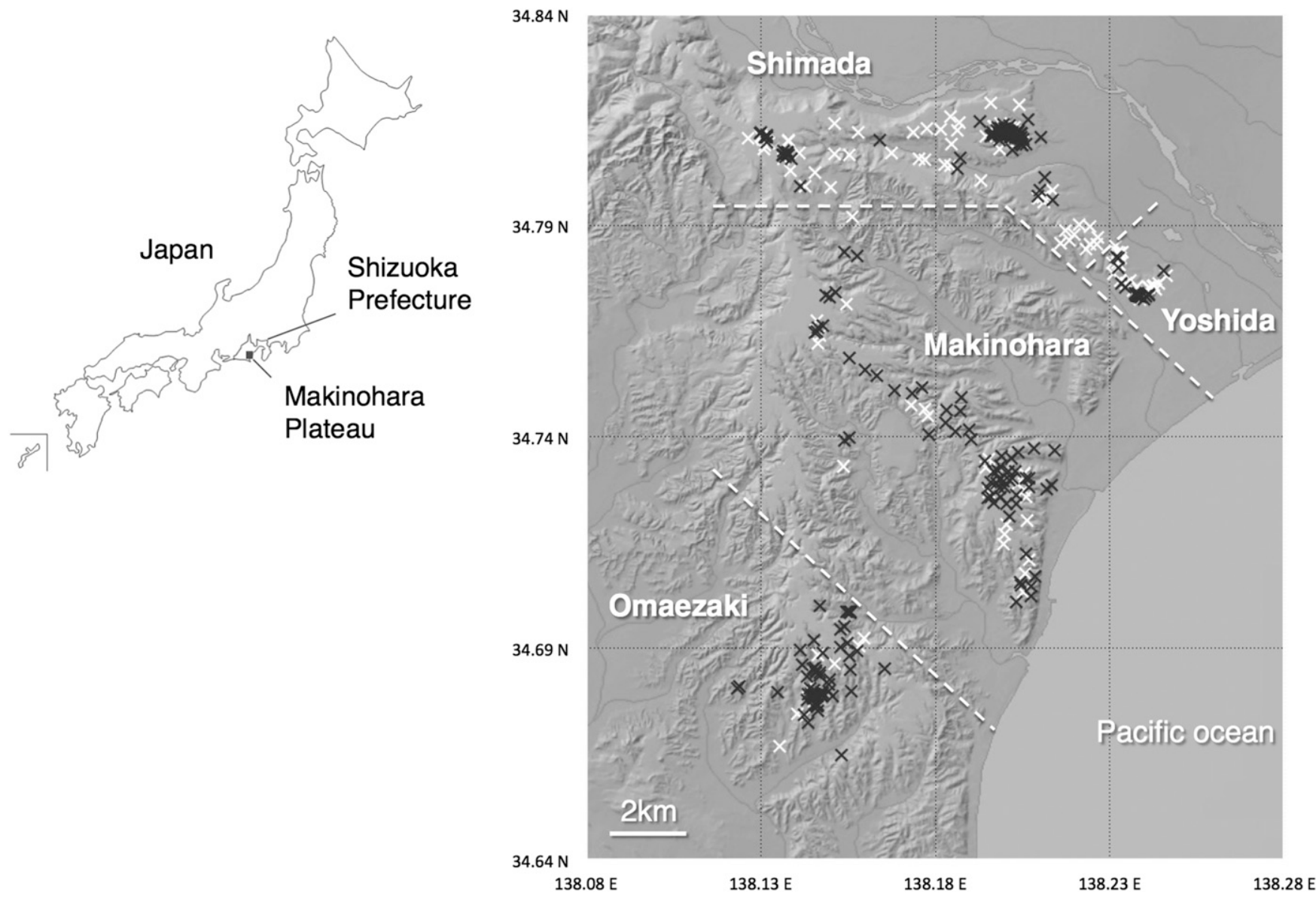

Fig. 1. Geographical locations of the study tea fields on the Makinohara Plateau, Shizuoka Prefecture, Japan. Black crosses denote fields in which any Pestalotiopsis longiseta isolates resistant to the quinone outside inhibitor (Qol) fungicides were detected. White crosses denote the fields in which only Qol-sensitive isolates were detected. White dotted lines denote the boundary between the regional groups set in this study. 
in a 20- $\mu$ l reaction volume. The PCR cycling conditions consisted of an initial denaturation at $95^{\circ} \mathrm{C}$ for $5 \mathrm{~min}, 35$ cycles at $94^{\circ} \mathrm{C}$ for $1 \mathrm{~min}$, annealing for $1 \mathrm{~min}, 72^{\circ} \mathrm{C}$ for $2 \mathrm{~min}$, and a final extension at $72^{\circ} \mathrm{C}$ for 10 min. Annealing temperatures were $53.5^{\circ} \mathrm{C}$ for CGA and $\mathrm{CCA}$, and $49^{\circ} \mathrm{C}$ for GT (Takatsuka 2007). The amplification products were separated by electrophoresis on $1.0 \%$ agarose gels (Agarose S, Nippon Gene, Tokyo) with $0.5 \times$ Tris-borate-EDTA buffer (Takara Bio, Otsu, Japan) and were stained with ethidium bromide. The DNA bands were visualized by fluorescence under ultraviolet light. The size of the bands was estimated by comparison with a 200-bp DNA ladder (Takara Bio).

Highly resistant Moderately resistant Sensitive

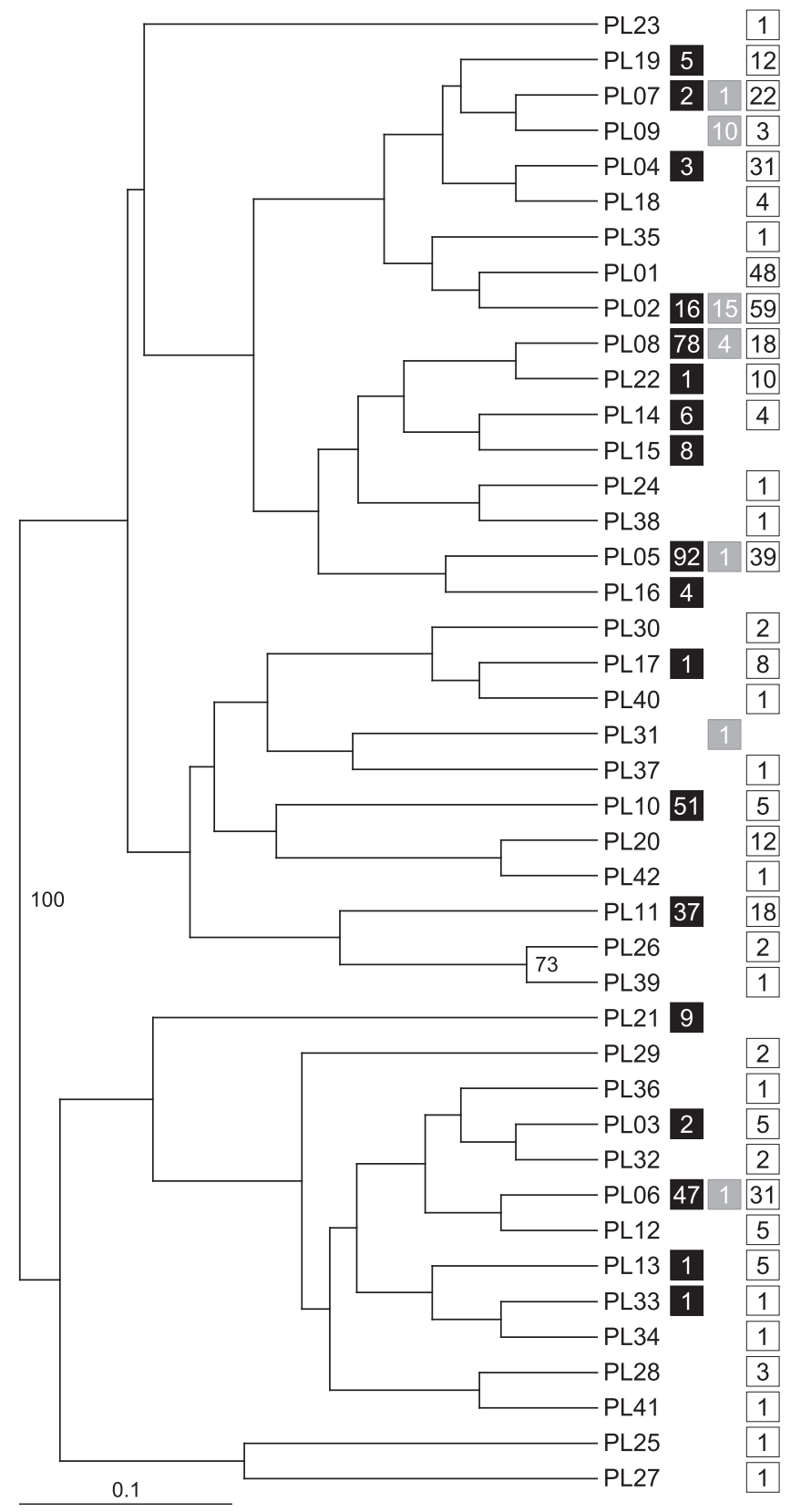

Fig. 2. An unweighted pair group method with arithmetic means dendrogram of Pestalotiopsis longiseta isolate inter simple sequence repeat (ISSR) types based on Nei and Li's similarity coefficient (Nei and Li 1979). Numbers of tea fields on the Makinohara Plateau, Shizuoka, Japan where the ISSR type with different quinone outside inhibitor sensitivities were detected are represented in boxes. Bootstrap values above $50 \%$ (1,000 repetitions) are represented at nodes.
Data analysis. ISSR fragments ranging in size from 400 to 3,000 bp that could be scored unambiguously were included in the analysis. Indistinct fragments that did not show a clear presence or absence pattern were excluded. ISSR banding patterns were scored visually and converted into binary data indicating either the presence (1) or absence (0) of each band. An unweighted pair group method with arithmetic means dendrogram based on Nei and Li's similarity coefficient (Nei and Li 1979) was constructed by FreeTree v. 0.9.1.50 (Pavlicek et al. 1999) and was visualized by TreeView v. 1.6.6 (Page 1996). The robustness of the dendrogram was assessed by bootstrap analysis with 1,000 repetitions. Analysis of molecular variance (AMOVA) was performed in Arlequin v. 3.5.1.3 (Excoffier and Lischer 2010), based on haplotype frequencies regarding ISSR type as haplotype and field as population, because tea plants are dense in small fields (about $1,000 \mathrm{~m}^{2}$ ) and are managed uniformly in each field. To analyze the annual changes in population structure, isolates collected from the same field in the same year were regarded as a population. Significance of variance components and fixation indices were assessed by 1,023 permutations.

\section{Results}

ISSR analysis of $\boldsymbol{P}$. longiseta isolates. ISSR analysis of 1,082 isolates, in total, collected in 395 fields from 2009 to 2012, using three primers, yielded 34 bands ranging in size from 400 to $3,000 \mathrm{bp}$, of which $16(47 \%)$ were polymorphic. A combination of polymorphic bands produced 42 distinctly different ISSR types, designated as PL01 to PL42 (Fig. 2; Table 1). Eighteen ISSR types were detected in the HR, seven in the MR, and 38 in the $\mathrm{S}$ isolates. Three, one, and 22 ISSR types were only detected in the HR, MR, and S isolates, respectively. Five ISSR types were common to all three QoI sensitivity groups, 10 were common to the $\mathrm{HR}$ and $\mathrm{S}$ isolates, and one was common to the MR and S isolates. Multiple ISSR types were usually detected in a field. The average haplotype diversities in a field were $0.85,0.17$, and 0.51 for the $S, M R$, and HR isolates, respectively. No distinct phylogenetic relationship corresponding to QoI sensitivity or sampling location was observed (Fig. 2; Table 1).

Geographical distribution of ISSR types. The percentage of fields in which each ISSR type with different QoI sensitivity was detected in each regional group is shown in Table 1. The predominant ISSR type among the HR isolates differed regionally. In Shimada, PL05 was predominant among the HR isolates, being detected in $69 \%$ of the fields. PL05 was also detected in Yoshida and Makinohara at lower frequencies (26 and 28\%) but not in Omaezaki. In contrast, PL10 was predominant among the HR isolates in Omaezaki being detected in $68 \%$ of the fields. PL10 was also detected in other regions, but frequencies were much lower ( 3 to $12 \%$ ). In Makinohara, the genetic structure was intermediate between Shimada and Omaezaki. The most common ISSR type among the HR isolates was PL06 (38\%), which was also detected in Shimada and Omaezaki at lower frequencies (6 and $28 \%$, respectively). The second and third most common ISSR types in Makinohara were PL05 and PL10; they were predominant in Shimada and Omaezaki, respectively. In Yoshida, the predominant ISSR type was PL11 (48\%). It was also detected in the other regions but at much lower frequencies (5 to 17\%). AMOVA of the HR isolates regarding fields as populations and dividing into four regional groups revealed significant population differentiation among regional groups. The fixation index among groups $\left(F_{C T}=\right.$ 0.213 ) was higher than that among populations within groups $\left(F_{S C}=0.128\right)($ Table 2$)$.

MR isolates were detected in 24 fields in Omaezaki and three fields in Makinohara. A total of seven ISSR types were detected among 64 isolates from these 27 fields (Table 1). In Omaezaki, PL02 and PL09 were most common among a total of four ISSR types detected. They were detected in 58 and $42 \%$ of fields, respectively. Both PL02 and PL09 were detected in 13\% of fields. In Makinohara, four ISSR types were detected among six isolates from three fields. Only PL02 was shared between Makinohara and Omaezaki. Although we could not examine differentiation between regions by AMOVA because most of the MR isolates were detected in Omaezaki, 
a few of the predominant ISSR types were common to both the MR and HR isolates.

Population differentiation of HR isolates among farmers. We analyzed 19 fields in the Sakamoto section of Shimada. PL05 and PL08, the most common ISSR types in Shimada, were also frequent in this section. PL05 was detected in all 19 fields and PL08 was detected in 17 fields. AMOVA was performed by dividing fields into six groups according to farmer. Significant population differentiation was revealed among the six groups, although the fixation index $\left(F_{C T}=0.071\right)$ was low (Table 2$)$. The fixation index among fields within groups $\left(F_{S C}=-0.013\right)$ was very low and there was no significant differentiation.

Annual changes in HR isolate population genetic structure. AMOVA was performed on HR isolates collected in the same field for two years and divided into groups by collection year. Analysis of 30 populations, consisting of $112 \mathrm{HR}$ isolates collected in 15 fields in Omaezaki in 2009 and 2010, and 24 populations, consisting of 110 HR isolates collected in 12 fields in Shimada in 2010 and 2011, resulted in very low fixation indices between annual groups, $F_{C T}=$ -0.010 and -0.000 for 2009/2010 (Omaezaki) and 2010/2011 (Shimada), respectively (Table 3 ).

\section{Discussion}

This is the first study of DNA fingerprinting and population genetic analysis in $P$. longiseta. A number of ISSR types were detected from $P$. longiseta isolates originating from tea gray blight lesions. ISSRs are nuclear DNA markers (Ziętkiewicz et al. 1994), whereas QoI resistance is caused by mitochondrial cytb gene mutations (Fernández-Ortuño et al. 2010; Gisi et al. 2002). Conidia are considered to play a key role in the disease cycle of Pestalotiopsis spp.,

Table 1. Geographical distribution of Pestalotiopsis longiseta inter simple sequence repeat (ISSR) types with different quinone outside inhibitor (QoI) fungicide sensitivities among tea fields in four regions on the Makinohara Plateau, Shizuoka, Japan from 2009 to $2012^{\mathbf{a}}$

\begin{tabular}{|c|c|c|c|c|c|c|c|c|c|c|}
\hline \multirow[b]{2}{*}{ ISSR type } & \multicolumn{4}{|c|}{ Highly resistant } & \multicolumn{2}{|c|}{$\begin{array}{l}\text { Moderately } \\
\text { resistant }\end{array}$} & \multicolumn{4}{|c|}{ Sensitive } \\
\hline & $\mathbf{S}$ & $\mathbf{Y}$ & M & $\mathbf{O}$ & $\bar{M}$ & $\overline{0}$ & $\mathbf{S}$ & $\mathbf{Y}$ & $\mathbf{M}$ & $\mathbf{O}$ \\
\hline PL01 & $\ldots$ & $\ldots$ & $\ldots$ & $\ldots$ & $\ldots$ & $\ldots$ & 18 & 8 & 18 & 10 \\
\hline PL02 & 7 & 4 & 11 & 2 & 33 & 58 & 19 & 18 & 17 & 21 \\
\hline PL03 & $\ldots$ & $\ldots$ & $\ldots$ & 4 & $\ldots$ & $\ldots$ & 1 & 3 & 3 & 2 \\
\hline PL04 & 3 & $\ldots$ & $\ldots$ & $\ldots$ & $\ldots$ & $\ldots$ & 6 & 15 & 21 & 2 \\
\hline PL05 & 69 & 26 & 28 & $\ldots$ & $\ldots$ & 4 & 21 & 18 & 4 & $\ldots$ \\
\hline PL06 & 6 & $\ldots$ & 38 & 28 & 33 & $\ldots$ & 14 & 15 & 3 & 7 \\
\hline PL07 & $\ldots$ & $\ldots$ & $\ldots$ & 4 & 33 & $\ldots$ & 6 & 5 & 10 & 5 \\
\hline PL08 & 43 & 17 & 11 & 42 & $\ldots$ & 17 & 5 & 5 & 6 & 7 \\
\hline PL09 & $\ldots$ & $\ldots$ & $\ldots$ & $\ldots$ & $\ldots$ & 42 & $\ldots$ & $\ldots$ & $\ldots$ & 5 \\
\hline PL10 & 3 & 4 & 12 & 68 & $\ldots$ & $\ldots$ & $\ldots$ & 3 & 3 & 3 \\
\hline PL11 & 17 & 48 & 5 & 11 & $\ldots$ & $\ldots$ & 4 & $\ldots$ & 5 & 15 \\
\hline PL12 & $\ldots$ & $\ldots$ & $\ldots$ & $\ldots$ & $\ldots$ & $\ldots$ & 1 & 3 & 3 & 2 \\
\hline PL13 & $\ldots$ & $\ldots$ & 2 & $\ldots$ & $\ldots$ & $\ldots$ & 4 & $\ldots$ & $\ldots$ & $\ldots$ \\
\hline PL14 & 3 & $\ldots$ & 3 & 2 & $\ldots$ & $\ldots$ & 2 & $\ldots$ & 1 & $\ldots$ \\
\hline PL15 & 1 & $\ldots$ & 8 & 4 & $\ldots$ & $\ldots$ & $\ldots$ & $\ldots$ & $\ldots$ & $\ldots$ \\
\hline PL16 & $\ldots$ & $\ldots$ & 6 & $\ldots$ & $\ldots$ & $\ldots$ & $\ldots$ & $\ldots$ & $\ldots$ & $\ldots$ \\
\hline PL17 & $\ldots$ & $\ldots$ & $\ldots$ & 2 & $\ldots$ & $\ldots$ & 3 & $\ldots$ & $\ldots$ & 7 \\
\hline PL18 & $\ldots$ & $\ldots$ & $\ldots$ & $\ldots$ & $\ldots$ & $\ldots$ & $\ldots$ & $\ldots$ & $\ldots$ & 7 \\
\hline PL19 & 2 & $\ldots$ & 2 & 4 & $\ldots$ & $\ldots$ & 1 & & 4 & 11 \\
\hline PL20 & $\ldots$ & $\ldots$ & $\ldots$ & $\ldots$ & $\ldots$ & $\ldots$ & 2 & $\ldots$ & 5 & 8 \\
\hline PL21 & 9 & $\ldots$ & $\ldots$ & $\ldots$ & $\ldots$ & $\ldots$ & $\ldots$ & $\ldots$ & $\ldots$ & $\ldots$ \\
\hline PL22 & 1 & $\ldots$ & $\ldots$ & $\ldots$ & $\ldots$ & $\ldots$ & 4 & $\ldots$ & 4 & 2 \\
\hline PL23 & $\ldots$ & $\ldots$ & $\ldots$ & $\ldots$ & $\ldots$ & $\ldots$ & $\ldots$ & $\ldots$ & $\ldots$ & 2 \\
\hline PL24 & $\ldots$ & $\ldots$ & $\ldots$ & $\ldots$ & $\ldots$ & $\ldots$ & $\ldots$ & & 1 & $\ldots$ \\
\hline PL25 & $\ldots$ & $\ldots$ & $\ldots$ & $\ldots$ & $\ldots$ & $\ldots$ & 1 & $\ldots$ & $\ldots$ & $\ldots$ \\
\hline PL26 & $\ldots$ & $\ldots$ & $\ldots$ & $\ldots$ & $\ldots$ & $\ldots$ & $\ldots$ & $\ldots$ & 1 & 2 \\
\hline PL27 & $\ldots$ & $\ldots$ & $\ldots$ & $\ldots$ & $\ldots$ & $\ldots$ & $\ldots$ & $\ldots$ & $\ldots$ & 2 \\
\hline PL28 & $\ldots$ & $\ldots$ & $\ldots$ & $\ldots$ & $\ldots$ & $\ldots$ & 1 & $\ldots$ & 1 & 2 \\
\hline PL29 & $\ldots$ & $\ldots$ & $\ldots$ & $\ldots$ & $\ldots$ & $\ldots$ & $\ldots$ & $\ldots$ & 3 & $\ldots$ \\
\hline PL30 & $\ldots$ & $\ldots$ & $\ldots$ & $\ldots$ & $\ldots$ & $\ldots$ & $\ldots$ & $\ldots$ & 3 & $\ldots$ \\
\hline PL31 & $\ldots$ & $\ldots$ & $\ldots$ & $\ldots$ & 33 & $\ldots$ & $\ldots$ & $\ldots$ & $\ldots$ & $\ldots$ \\
\hline PL32 & $\ldots$ & $\ldots$ & $\ldots$ & $\ldots$ & $\ldots$ & $\ldots$ & 1 & $\ldots$ & $\ldots$ & 2 \\
\hline PL33 & $\ldots$ & $\ldots$ & 2 & $\ldots$ & $\ldots$ & $\ldots$ & 1 & $\ldots$ & $\ldots$ & $\ldots$ \\
\hline PL34 & $\ldots$ & $\ldots$ & $\ldots$ & $\ldots$ & $\ldots$ & $\ldots$ & 1 & $\ldots$ & $\ldots$ & $\ldots$ \\
\hline PL35 & $\ldots$ & $\ldots$ & $\ldots$ & $\ldots$ & $\ldots$ & $\ldots$ & $\ldots$ & 3 & $\ldots$ & $\ldots$ \\
\hline PL36 & $\ldots$ & $\ldots$ & $\ldots$ & $\ldots$ & $\ldots$ & $\ldots$ & $\ldots$ & $\ldots$ & 1 & $\ldots$ \\
\hline PL37 & $\ldots$ & $\ldots$ & $\ldots$ & $\ldots$ & $\ldots$ & $\ldots$ & 1 & $\ldots$ & $\ldots$ & $\ldots$ \\
\hline PL38 & $\ldots$ & $\ldots$ & $\ldots$ & $\ldots$ & $\ldots$ & $\ldots$ & $\ldots$ & 3 & $\ldots$ & $\ldots$ \\
\hline PL39 & $\cdots$ & $\cdots$ & $\begin{array}{l}\cdots \\
\ldots\end{array}$ & $\begin{array}{l}\cdots \\
\ldots\end{array}$ & $\cdots$ & $\begin{array}{l}\cdots \\
\ldots\end{array}$ & $\begin{array}{l}\cdots \\
\ldots\end{array}$ & 3 & $\begin{array}{l}\cdots \\
\ldots\end{array}$ & $\cdots$ \\
\hline PL40 & $\ldots$ & $\ldots$ & $\ldots$ & $\ldots$ & $\ldots$ & $\ldots$ & $\ldots$ & 3 & $\ldots$ & $\ldots$ \\
\hline PL41 & $\ldots$ & $\ldots$ & $\ldots$ & $\ldots$ & $\ldots$ & $\ldots$ & $\ldots$ & $\ldots$ & 1 & $\ldots$ \\
\hline PL42 & $\ldots$ & $\ldots$ & $\ldots$ & $\ldots$ & $\ldots$ & $\ldots$ & $\ldots$ & $\ldots$ & $\ldots$ & 2 \\
\hline Number of fields & 99 & 23 & 65 & 57 & 3 & 24 & 140 & 40 & 78 & 61 \\
\hline Number of isolates & 311 & 23 & 100 & 189 & 6 & 58 & 172 & 40 & 101 & 82 \\
\hline
\end{tabular}

${ }^{\text {a }}$ QoI sensitivity was assayed on potato dextrose agar containing the QoI fungicide azoxystrobin $(100 \mathrm{mg} / \mathrm{liter})$ and $n$-propyl gallate. The isolates that grew well were considered highly resistant. The completely inhibited isolates were considered sensitive. The isolates exhibiting intermediate growth were considered moderately resistant. $\mathrm{S}$ = Shimada, $\mathrm{Y}=$ Yoshida, $\mathrm{M}=$ Makinohara, $\mathrm{O}=$ Omaezaki. Values are the percentage of fields where the ISSR type was detected. 
because the sexual stage of Pestalotiopsis spp. rarely develops and has never been recorded for most species, including $P$. longiseta (Maharachchikumbura et al. 2011). Consequently, we hypothesized that the different ISSR types likely reflect differences in isolate clonal lineages and that both nuclear and mitochondrial DNA are usually transmitted to offspring through clonal reproduction in $P$. longiseta. The fact that a few ISSR types predominated among QoI-resistant isolates, combined with the annual stability in population genetic structure we observed, supports this inference (Taylor et al. 1999). No distinct phylogenetic relationship was observed among the QoI-resistant isolates on the dendrogram. Consequently, we hypothesize that QoI resistance occurred independently in a number of $P$. longiseta clonal lineages on the Makinohara Plateau.

Predominance of a particular strain among fungicide-resistant strains in asexual fungal species has been observed in previous studies. Kim et al. (2003) examined QoI-resistant Pyricularia grisea isolates infecting perennial ryegrass in Kentucky and some nearby states. $P$. grisea populations on perennial ryegrass are considered asexual (Viji et al. 2001). DNA fingerprinting obtained five DNA types from $14 \mathrm{HR}$ isolates and three types from six MR isolates, of which nine and four isolates, respectively, belonged to a particular type. Similar findings have been reported in scytalone dehydratase inhibitors of melanin biosynthesis (MBI-D), another fungicide class. As with QoI resistance, MBI-D resistance is caused by a single nucleotide substitution (Takagaki et al. 2004). Suzuki et al. (2007) examined MBI-Dresistant Pyricularia oryzae isolates infecting rice in Saga Prefecture, Japan from 2002 to 2003. P. oryzae populations on rice are considered asexual (Nottéghem et al. 1994; Suzuki et al. 2009). Among a total of 24 DNA types obtained from resistant isolates, the most frequent one was found in $72.0 \%$ (2002) and 56.5\% (2003) of the fields. The population structure of MBI-D-resistant $P$. oryzae was also examined in Mie Prefecture, Japan in 2006 to 2007 (Suzuki et al. 2012). Of the 21 types found, the most frequent one was found in $66.2 \%$ (2006) and $75.5 \%$ (2007) of the fields.

In the present study, PL05, the most frequent ISSR type among the HR isolates, was detected in only $37.7 \%$ (92/244) of fields where HR isolates were detected. This is presumably because of the pathogen's mode of transmission. The above-mentioned $P$. oryzae is seed- and airborne; therefore, a prevalent strain in a seed farm can spread rapidly and widely. In contrast, host plantmediated transmission of tea pathogens rarely occurs, because tea is a perennial crop that is cultivated for several decades after planting (Rural Culture Association 2008). P. longiseta conidia disperse with rain splash (Ezuka and Ando 1994; Horikawa 1986c). Accordingly, the natural transmission velocity and distance is estimated to be slower and shorter than airborne pathogens (Madden 1992; McCartney et al. 2006). The main route of spread among tea fields is thought to be plucking machine-mediated transmission, because plucking machines can be contaminated with pathogens while plucking fields where gray blight occurs and they inflict numerous wounds on tea plants, leaving them susceptible to infection (Ezuka and Ando 1994; Hamaya and Horikawa 1982; Horikawa 1984). The population differentiation in the HR isolates observed among farmers but not among fields within farmers in this study supports the importance of this route of transmission. The plucking machines can also facilitate long-distance transmission, because farmers commonly manage distant tea fields located in the different regional groups set in this study (R. Sonoda and $\mathrm{K}$. Yamada, personal observation).

In addition to artificial transmission, this study indicated that natural transmission is also involved in the spread of QoI-resistant strains, because a different ISSR type was predominant among the HR isolates in each regional group, i.e., PL05 in Shimada, PL11 in Yoshida, PL06 in Makinohara, and PL10 in Omaezaki. A similar situation was observed among MR isolates; PL02 and PL09 were predominant in Omaezaki and other types were detected in Makinohara. Furthermore, the fixation index among regions was much higher than that among farmers. Although the samples were collected for several years, this geographical difference is probably not the result of temporal factors, because no annual changes in population genetic structure of HR isolates within each regional group were observed during the study period. It is unlikely that plucking machines transmit HR isolates throughout each region, because small-scale individual farmers generally manage tea fields and sharing of plucking machines is not common because of the short harvesting time in the study area (R. Sonoda and K. Yamada, personal observation). These factors indicate that the predominance of a different ISSR type in each regional group is the result of natural transmission of the pathogen.

Table 2. Analysis of molecular variance (AMOVA) of quinone outside inhibitor (QoI)-highly resistant Pestalotiopsis longiseta populations collected in tea fields on the Makinohara Plateau, Shizuoka, Japan, grouped by region and farmer ${ }^{\mathrm{a}}$

\begin{tabular}{|c|c|c|c|c|c|}
\hline Source of variation & D.f. & Sum of squares & Variance components & Percentage of variation & Fixation indices \\
\hline \multicolumn{6}{|l|}{ Grouping by region } \\
\hline Among groups & 3 & 37.99 & $0.093 * * *$ & 21.26 & $F_{C T}=0.213 * * *$ \\
\hline Among populations within groups & 240 & 98.69 & $0.044 * * *$ & 10.12 & $F_{S C}=0.128 * * *$ \\
\hline Within populations & 380 & 113.83 & $0.300 * * *$ & 68.62 & $F_{S T}=0.314 * * *$ \\
\hline \multicolumn{6}{|l|}{ Grouping by farmer } \\
\hline Among groups & 5 & 3.62 & $0.021 *$ & 7.13 & $F_{C T}=0.071^{*}$ \\
\hline Among populations within groups & 13 & 3.28 & -0.004 & -1.25 & $F_{S C}=-0.013$ \\
\hline Within populations & 119 & 33.19 & 0.279 & 94.12 & $F_{S T}=0.059$ \\
\hline
\end{tabular}

${ }^{\text {a }}$ Isolates collected from the same field were regarded as a population. Populations were divided into four regional groups as shown in Figure 1 or six groups according to farmer. D.f. $=$ degrees of freedom. $* P<0.05, * * P<0.01, * * * P<0.001$ (1,023 permutations).

Table 3. Analysis of molecular variance (AMOVA) of quinone outside inhibitor (QoI)-highly resistant Pestalotiopsis longiseta populations collected in tea fields on the Makinohara Plateau, Shizuoka, Japan, grouped by collection year ${ }^{\mathrm{a}}$

\begin{tabular}{|c|c|c|c|c|c|}
\hline Source of variation & D.f. & Sum of squares & Variance components & Percentage of variation & Fixation indices \\
\hline \multicolumn{6}{|l|}{ 2009/2010 (Omaezaki) } \\
\hline Among groups & 1 & 0.31 & -0.003 & -0.95 & $F_{C T}=-0.010$ \\
\hline Among populations within groups & 28 & 12.92 & $0.049 * *$ & 14.85 & $F_{S C}=0.147 * *$ \\
\hline Within populations & 82 & 23.10 & $0.282 * *$ & 86.10 & $F_{S T}=0.139 * *$ \\
\hline \multicolumn{6}{|l|}{ 2010/2011 (Shimada) } \\
\hline Among groups & 1 & 0.35 & -0.000 & -0.02 & $F_{C T}=-0.000$ \\
\hline Among populations within groups & 22 & 7.70 & 0.007 & 2.00 & $F_{S C}=0.020$ \\
\hline Within populations & 86 & 27.55 & 0.320 & 98.02 & $F_{S T}=0.020$ \\
\hline
\end{tabular}

a Isolates were collected for two years in each field. Isolates collected in the same field in the same year were regarded as a population. D.f. $=$ degrees of freedom. $* P<0.05, * * P<0.01, * * * P<0.001$ (1,023 permutations). 
From the above, both artificial and natural transmission of $P$. longiseta among tea fields have likely occurred at a considerable frequency. Although the fungal spores dispersed by rain splash mostly land within < $1 \mathrm{~m}$ (Madden 1992; McCartney et al. 2006), P. longiseta conidia likely reach neighboring fields, because tea fields in this area are typically adjacent to each other and do not have any distinct partitions ( R. Sonoda and K. Yamada, personal observation). Once a conidium of a certain QoI-resistant strain migrates from one field to the edge of an adjacent field and successfully infects a plant and forms a lesion, the migrant strain can be spread rapidly throughout the field by plucking machines. It can then become predominant under selection pressure by QoI application and be naturally or artificially transmitted to other fields, eventually spreading throughout the region. It has been reported that QoI resistance is not associated with fitness costs in field isolates from several plant pathogens (FernándezOrtuño et al. 2010). Similarly, no fitness costs have been observed in QoI-resistant P. longiseta as far as we know. The mode of transmission is not likely to differ between QoI-sensitive and -resistant strains. Consequently, this infection cycle inferred from the analysis of QoI-resistant isolates can be generalized to the epidemiological behavior of tea gray blight causing $P$. longiseta.

In conclusion, we deduce that QoI-resistant $P$. longiseta strains have spread by both artificial and natural routes of transmission in each region on the Makinohara Plateau. It is thought that the main route of transmission of $P$. longiseta among fields is artificial transmission by plucking machine. Furthermore, we infer that natural transmission by rain splash also plays an important role. Both modes of transmission should be considered to prevent the spread of QoI-resistant $P$. longiseta strains among tea fields within and between tea-growing areas.

\section{Literature Cited}

Ando, Y., Narisawa, N., and Oniki, M. 1987. Etiology of shoot blight of tea plant occurred recently. Ann. Phytopathol. Soc. Jpn. 53:258-261.

Bartlett, D. W., Clough, J. M., Godwin, J. R., Hall, A. A., Hamer, M., and ParrDobrzanski, B. 2002. The strobilurin fungicides. Pest Manag. Sci. 58:649-662.

Brent, K. J., and Hollomon, D. W. 2007. Fungicide resistance: The assessment of risk, 2nd Ed. Fungicide Resistance Action Committee, Brussels, Belgium.

Excoffier, L., and Lischer, H. E. L. 2010. Arlequin suite ver 3.5: A new series of programs to perform population genetics analyses under Linux and Windows. Mol. Ecol. Resour. 10:564-567.

Ezuka, A., and Ando, Y. 1994. Tea Diseases in Japan. Japan Plant Protection Association, Tokyo.

Fernández-Ortuño, D., Torés, J. A., de Vicente, A., and Pérez-García, A. 2010. The QoI fungicides, the rise and fall of a successful class of agricultural fungicides. Pages 203-220 in: Fungicides. O. Carisse, ed. InTech, Rijeka, Croatia.

Fungicide Resistance Action Committee. 2013. List of plant pathogenic organisms resistant to disease control agents. Crop Life International, Brussels. Online publication. http://www.frac.info/publications/downloads

Gisi, U., Sierotzki, H., Cook, A., and McCaffery, A. 2002. Mechanisms influencing the evolution of resistance to Qo inhibitor fungicides. Pest Manag. Sci. 58:859-867.

Hamaya, E., and Horikawa, T. 1982. Gray blight of tea plant caused by Pestalotia longiseta Spegazzini. Study Tea 62:21-27.

Hantula, J., Dusabenyagasani, M., and Hamelin, R. C. 1996. Random amplifyied microsatellites (RAMS) - A novel method for characterizeing genetic variation within fungi. Eur. J. Forest Pathol. 26:159-166.

Heaney, S. P., Hall, A. A., Davies, S. A., and Olaya, G. 2000. Resistance to fungicides in the QoI-STAR cross-resistance group: current perspectives. Pages 755-762 in: The BCPC Conference: Pest and Diseases, Vol. 2. British Crop Protection Council, Farnham, Surrey, U.K.

Hollomon, D. W., Wood, P. M., Reeve, C., and Miguez, M. 2005 Alternative oxidase and its impact on the activety of Qo and Qi site inhibitors. Pages 55-62 in: Modern Fungicides and Antifungal Compounds IV. 14th International Reinhardsbrunn Symposium, Friedrichroda, Thuringia, Germany, April 25-29, 2004. H. W. Dehne, U, Gisi, K. H. Kuck, P. E. Russell, and H. Lyr, eds. British Crop Protection Counsil, Alton, U.K.

Horikawa, T. 1982. Effective fungicides and application time for control of tea gray blight caused by Pestalotia longiseta Speg. Tea Res. J. 56:45-56.

Horikawa, T. 1984. Occurrence of tea gray blight caused by Pestalotia longiseta Speg. and its control. Plant Prot. 38:275-279.
Horikawa, T. 1986a. Yield loss of new tea shoots due to tea gray blight caused by Pestalotia longiseta Spegazzini. Bull. Shizuoka Tea Exp. Stn. 12:1-8.

Horikawa, T. 1986b. Occurrence of benzimidazole tolerant isolates of Pestalotia longiseta Spegazzini in tea fields. Bull. Shizuoka Tea Exp. Stn. 12:9-14.

Horikawa, T. 1986c. Production and vicissitudes of conidia of Pestalotia longiseta Spegazzini in the tea fields and removal effect of infection source by pruning. Bull. Shizuoka Tea Exp. Stn. 12:14-22.

Kim, Y.-S., Dixon, E. W., Vincelli, P., and Farman, M. L. 2003. Field resistance to strobilurin (QoI) fungicides in Pyricularia grisea caused by mutations in the mitochondrial cytochrome b gene. Phytopathology 93:891-900.

Madden, L. V. 1992. Rainfall and the dispersal of fungal spores. Pages 39-79 in: Advances in Plant Pathology. Andrews, J. H., and Tommerup, I. C., eds. Vol. 8. Academic Press, London, U.K

Maharachchikumbura, S. S. N., Guo, L.-D., Chukeatirote, E., Bahkali, A. H., and Hyde, K. D. 2011. Pestalotiopsis-Morphology, phylogeny, biochemistry and diversity. Fungal Divers. 50:167-187.

McCartney, H. A., Fitt, B. D. L., and West, J. S. 2006. Dispersal of foliar plant pathogens: mechanisms, gradients and spatial patterns. Pages 159-192 in: The Epidemiology of Plant Diseases, 2nd edition. B. M. Cooke, D. Gareth Jones, and B., Kaye, eds. Springer, Dordrecht, The Netherlands.

Nei, M., and Li, W.-N. 1979. Mathematical model for studying genetic variation in terms of restriction endonucleases. Proc. Natl Acad. Sci. U.S. A. 76.5269-5273.

Nottéghem, J. L., Tharreau, D., Silué, D., and Roumen, E. H. 1994. Present knowledge of rice resistance genetics and strategyes for Magnaporthe grisea pathogenicity and avirulence gene analysis. Pages 155-165 in: Rice Blast Disease. R. S. Zeigler, S. A. Leong, and P. S. Teng, eds. CAB International, Wallingford, U.K.

Oniki, M., Narisawa, N., and Ando, Y. 1986. Incidence of strains of the tea gray blight fungi Pestalotia longiseta and $P$. theae resistant to benzimidazole fungicides in Japan. Tea Res. J. 64:29-33.

Page, R. D. M. 1996. TREEVIEW: An application to display phylogenetic trees on personal computers. Comput. Appl. Biosci. 12:357-359.

Pavlicek, A., Hrda, S., and Flegr, J. 1999. FreeTree-Freeware program for construction of phylogenetic trees on the basis of distance data and bootstrap/ jackknife analysis of the tree robustness. Application in the RAPD analysis of the genus Frenkelia. Folia Biol. (Praha) 45:97-99.

Rural Culture Association, ed. 2008. Cha Daihyakka II. Rural Culture Association, Tokyo.

Sonoda, R., and Yamada, K. 2012. Distribution of QoI-resistant strains of Pestalotiopsis longiseta in Makinohara Plateau of Shizuoka Pref. in 2009 2011. Jpn. J. Phytopathol. 78:200.

Suzuki, F., Arai, M., and Yamaguchi, J. 2007. Genetic analysis of Pyricularia grisea population by rep-PCR during development of resistance to scytalone dehydratase inhibitors of melanin biosynthesis. Plant Dis. 91:176-184.

Suzuki, F., Suga, H., Tomimura, K., Fuji, S., Arai, M., Koba, A., and Nakajima, T. 2009. Development of simple sequence repeat markers for Japanese isolates of Magnaporthe grisea. Mol. Ecol. Resour. 9:588-590.

Suzuki, H., Suzuki, F., Kusaba, M., and Tosa, Y. 2012. Population structure of rice blast isolates resistant to scytalone dehydratase inhibitors in Mie Prefecture and implications for their origin. J. Gen. Plant Pathol. 78:106-114.

Takagaki, M., Kaku, K., Watanabe, S., Kawai, K., Shimizu, T., Sawada, H., Kumakura, K., and Nagayama, K. 2004. Mechanism of resistance to carpropamid in Magnaporthe grisea. Pest Manag. Sci. 60:921-926.

Takatsuka, J. 2007. Characterization of Beuveria bassiana isolates from Japan using inter-simple-sequence-repeat-anchored polymerase chain reaction (ISSRPCR) amplification. Appl. Entomol. Zool. (Jpn.) 42:563-571

Taylor, J. W., Jacobson, D. J., and Fisher, M. C. 1999. The evolution of asexual fungi: Reproduction, speciation and classification. Annu. Rev. Phytopathol. 37:197-246.

Togawa, M. 2014. Relationship between the control effect and occurrence rate of azoxystrobin resistant strains of Pestalotiopsis longiseta (pathogen of shoot blight of tea). Ann. Rept. Kansai Pl. Prot. 56:63-64.

Togawa, M., Nishijima, T., and Katayama, H. 2010. Occurrence of strobilurin resistance of Pestalotiopsis longiseta, the causal fungus of tea gray blight, in Shizuoka Prefecture. Jpn. J. Phytopathol. 76:154.

Tomihama, T., Nonaka, T., Omatsu, N., and Nishi, Y. 2009. Occurrence of QoI resistance in Pestalotiopsis longiseta, the pathogen causing gray blight disease in tea plants. Kyushu Pl. Prot. Res. 55:83-88.

Viji, G., Wu, B., Kang, S., Uddin, W., and Huff, D. R. 2001. Pyricularia grisea causing gray leaf spot of perennial ryegrass turf: Population structure and host specificity. Plant Dis. 85:817-826.

Yamada, K., and Sonoda, R. 2012. Characterization of moderate resistance to QoI fungicides in Pestalotiopsis longiseta and polymorphism in exon-intron structure of cytochrome $b$ gene. J. Gen. Plant Pathol. 78:398-403.

Ziętkiewicz, E., Rafalski, A., and Labuda, D. 1994. Genome fingerprinting by simple sequence repeat (SSR)-anchored polymerase chain reaction amplification. Genomics 20:176-183. 